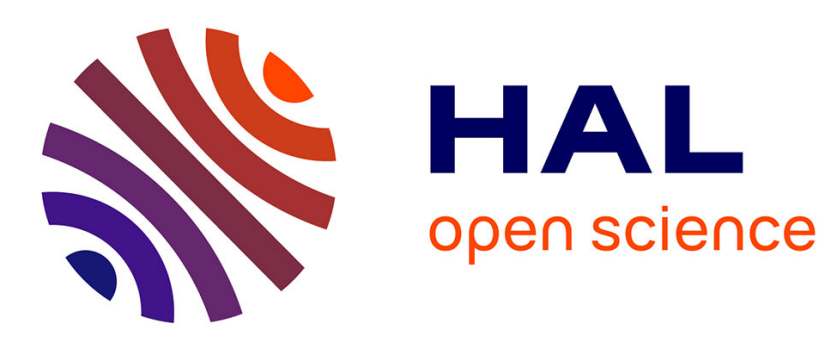

\title{
Direct adaptive rejection of unknown time-varying narrow band disturbances applied to a benchmark problem
}

Abraham Castellanos Silva, Ioan Doré Landau, Tudor-Bogdan Airimitoaie

\section{To cite this version:}

Abraham Castellanos Silva, Ioan Doré Landau, Tudor-Bogdan Airimitoaie. Direct adaptive rejection of unknown time-varying narrow band disturbances applied to a benchmark problem. European Journal of Control, 2013, 19 (4), pp.326-336. 10.1016/j.ejcon.2013.05.012 . hal-00829964

\section{HAL Id: hal-00829964 https://hal.science/hal-00829964}

Submitted on 15 Oct 2020

HAL is a multi-disciplinary open access archive for the deposit and dissemination of scientific research documents, whether they are published or not. The documents may come from teaching and research institutions in France or abroad, or from public or private research centers.
L'archive ouverte pluridisciplinaire HAL, est destinée au dépôt et à la diffusion de documents scientifiques de niveau recherche, publiés ou non, émanant des établissements d'enseignement et de recherche français ou étrangers, des laboratoires publics ou privés. 


\title{
Direct adaptive rejection of unknown time-varying narrow band disturbances applied to a benchmark problem
}

\author{
Abraham Castellanos Silva ${ }^{1}$, Ioan Doré Landau ${ }^{1}$, and Tudor-Bogdan Airimiţoaie ${ }^{1,2}$
}

\begin{abstract}
The paper presents a direct adaptive algorithm for the rejection of unknown time-varying narrow band disturbances, applied to an adaptive regulation benchmark. The objective is to minimize the residual force by applying an appropriate control signal on the inertial actuator in the presence of multiple and/or unknown time-varying disturbances. The direct adaptive control algorithm is based on the internal model principle (IMP) and uses the Youla-Kučera (YK) parametrization. A direct feedback adaptive regulation is proposed and evaluated both in simulation and real-time. The robustness is improved by shaping the sensitivity functions of the system through band stop filters (BSF).
\end{abstract}

Index Terms-Adaptive Regulation, Active Vibration Control, Inertial Actuators, Multiple Narrow Band Disturbances, YoulaKučera Parametrization, Internal Model Principle

\section{INTRODUCTION}

A basic problem in active vibration control is the attenuation (rejection) of multiple narrow band disturbances of unknown and time-varying frequencies. The energy of these disturbances (or vibrations) is concentrated in a narrow band around an unknown frequency and could be modelled as a white noise or a Dirac impulse passed through a model of the disturbance. While, in general, one can assume a certain structure for such model of disturbance, its parameters are unknown and may be time-varying. The need of an adaptive approach arises

This problem could be addressed using additional transducers to obtain an image of the perturbation (inspired by Widrow's technique for adaptive noise cancellation [29]) considering that the measurement is highly correlated with the unknown disturbance. This leads to a feedforward approach as in [5], [10], [11], [14]. The disadvantages of this approach are:

- Requires the use of an additional transducer.

- Difficult choice for the location of this transducer.

- Requires the adaptation of many parameters.

A feedback approach overcome these disadvantages providing disturbance rejection (at least asymptotically), using only the measurement of the residual force (acceleration) as in [1], [2], [22].

Different problem scenarios have been considered using a feedback solution and the model of the disturbance:

1) Unknown plant and disturbance model [12].

2) Unknown plant and known disturbance model [26], [30].

3) Known plant and unknown disturbance model [7], [1], [2], [28], [24], [9], [15], [16]

${ }^{1}$ Control system department of GIPSA-lab, St. Martin d'Héres, 38402 FRANCE (e-mail: [abraham.castellanos-silva, ioan-dore.landau,tudorbogdan.airimitoaie]@gipsa-lab.grenoble-inp.fr).

${ }^{2}$ Faculty of Automatic Control and Computers, University "Politehnica" of Bucharest, Bucharest, 060042 ROMANIA.
The present paper belongs to the third category, since the dynamic characteristics of the system are practically constant for a given physical realization. Also, very reliable estimates of the parameters of the control model can be obtained by standard system identification.

In this context, the following approaches have been considered for solving the problem of feedback regulation of unknown and time-varying narrow-band disturbances:

1) Use of the internal model principle [1], [2], [4], [13], [15], [16], [17], [22], [27], [28].

2) Use of an observer for the disturbance [9], [24], [8].

3) Use of the phase-locked loop structure considered in communications systems [7], [6].

Since the model of the perturbation is consider unknown, an adaptive implementation is required. Two approaches can be considered: direct or indirect.

Direct adaptive schemes require less computational time than indirect schemes and through the Youla-Kučera (YK) parametrization of the controller along with the Internal Model Principle (IMP), offer advantages as simpleness, excellent adaptation transients and closed loop stability during the adaptive regulation. This approach has been successfully used in a number of applications [22], [21], and therefore has been considered to be applied to the benchmark.

The YK parametrization (known also as the $Q$ parametrization) allows to insert and adjust the internal model of the disturbance into the controller by adjusting the parameters of the polynomial $\hat{Q}\left(z^{-1}\right)$ (see Fig. 3). The above is done without recomputing the central controller $\left(R_{0}\left(z^{-1}\right)\right.$ and $S_{0}\left(z^{-1}\right)$ in Fig. 3 remain unchanged). This also preserves the desired closed loop poles adding to the robustness of the control scheme. Also the number of parameters to be directly adapted is roughly equal to the number of parameters on the denominator disturbance model. The above means that the size of the adaptation algorithm will depend upon the complexity of the disturbance model.

The design that will be presented in this paper preserves the fixed parts in the nominal controller (as shown in [21]) and also shows how the robustness of the closed loop can be improved by chosing adequate Band-Stop Filters (BSF) for shaping the sensitivity functions.

The paper is organized as follows. Section II presents briefly the active suspension system using an inertial actuator on which the algorithms will be tested. Section III presents the general plant and controller structure in the context of the YK parametrization. The direct adaptive algorithm is revised in Section IV. Section V discusses briefly the design of the central controller using BSFs for shaping the sensitivity functions. Simulation results are presented in Section VI, 
while experimental results for this methodology are given in Section VII. Concluding remarks are presented in Section VIII.

\section{Active Vibration CONTROL System USing AN INERTIAL ACTUATOR}

The structure of the system used for the benchmark on adaptive regulation is presented in Fig. 1. A picture of the real system is presented in Fig. 2, on both figures the structure components are indicated. The system consist of a passive damper (indicated with the number 2 in Fig. 1), an inertial actuator (indicated with the number 3), a load, a transducer for the residual force, a controller, a power amplifier and a shaker (source of perturbation and indicated with the number 1). The

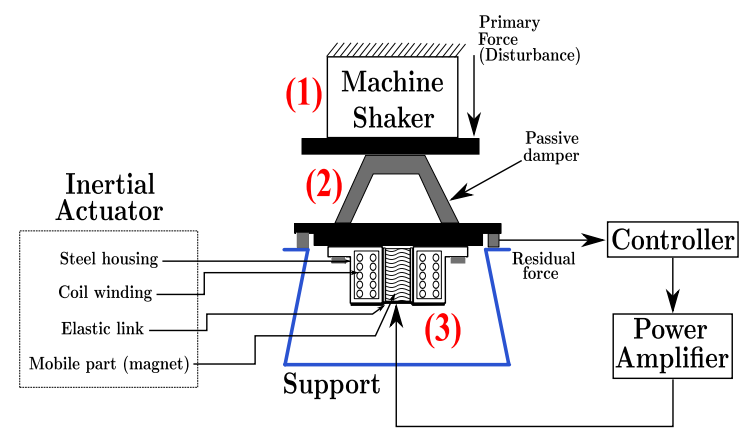

Fig. 1. Active vibration control (scheme)

control objective is to reject the effect of unknown narrowband disturbances on the output of the system (residual force), i.e., to attenuate the vibrations transmitted from the machine to the chassis. The transfer function $\left(N_{p}\left(z^{-1}\right) / D_{p}\left(z^{-1}\right)\right)$, between the disturbance force $\delta(t)$ and the residual force $y(t)$ is called primary path. The plant transfer function $\left(z^{-d} B\left(z^{-1}\right) / A\left(z^{-1}\right)\right)$ between the input of the inertial actuator, $u(t)$, and the residual force is called secondary path. The system is controlled in real-time using a MATLAB xPC target environment. The sampling frequency is $F_{S}=800 \mathrm{~Hz}$. For a detailed hardware description see [20], [19]. In [19] the LTI discrete time models

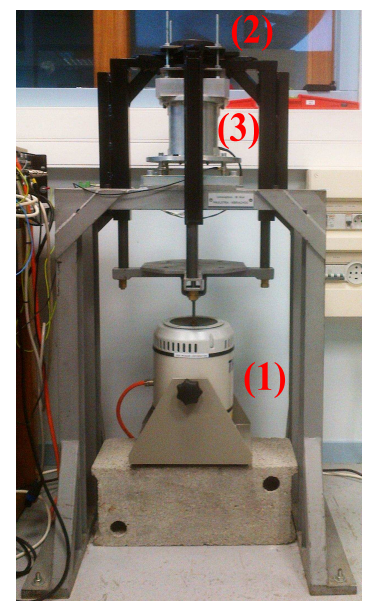

Fig. 2. Active vibration control (photograph)

for both paths are given ${ }^{1}$. The secondary path model presents a

${ }^{1}$ The primary path model is given for simulation purposes. number of low damped vibration modes as well as low damped complex zeros (anti-resonance).

\section{Plant Representation AND Controller STRUCTURE}

The structure of the LTI discrete time model of the plant, also called secondary path, used for controller design is

$$
G\left(z^{-1}\right)=\frac{z^{-d} B\left(z^{-1}\right)}{A\left(z^{-1}\right)}=\frac{z^{-d-1} B^{*}\left(z^{-1}\right)}{A\left(z^{-1}\right)},
$$

where

$$
\begin{aligned}
A\left(z^{-1}\right) & =1+a_{1} z^{-1}+\cdots+a_{n_{A}} z^{-n_{A}}, \\
B\left(z^{-1}\right) & =b_{1} z^{-1}+\cdots+b_{n_{B}} z^{-n_{B}}=z^{-1} B^{*}, \\
B^{*} & =b_{1}+\cdots+b_{n_{B}} z^{-n_{B}+1},
\end{aligned}
$$

and $d$ is the plant pure time delay in number of sampling periods ${ }^{2}$.

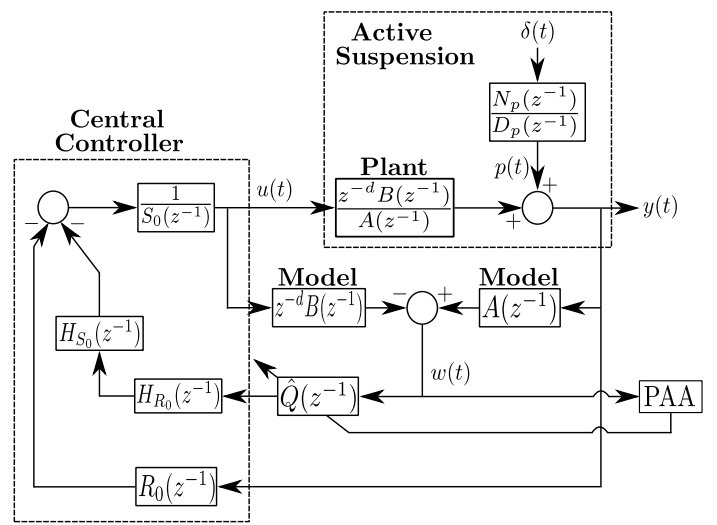

Fig. 3. Direct adaptive regulation scheme for rejection of unknown disturbances

Without considering a reference signal, the output of the plant $y(t)$ and the input $u(t)$ may be written as (see Fig. 3):

$$
\begin{aligned}
y(t) & =\frac{q^{-d} B\left(q^{-1}\right)}{A\left(q^{-1}\right)} \cdot u(t)+p(t), \\
S_{0}\left(q^{-1}\right) \cdot u(t) & =-R_{0}\left(q^{-1}\right) \cdot y(t) .
\end{aligned}
$$

In (5), $p(t)$ is the effect of the disturbances on the measured output ${ }^{3}$ and $R_{0}\left(z^{-1}\right), S_{0}\left(z^{-1}\right)$ are polynomials in $z^{-1}$ having the following expressions ${ }^{4}$ :

$$
\begin{aligned}
& S_{0}=1+s_{1}^{0} z^{-1}+\ldots+s_{n_{S}}^{0} z^{-n_{S}}=S_{0}^{\prime}\left(z^{-1}\right) \cdot H_{S_{0}}\left(z^{-1}\right), \\
& R_{0}=r_{0}^{0}+r_{1}^{0} z^{-1}+\ldots+r_{n_{R}}^{0} z^{-n_{R}}=R_{0}^{\prime}\left(z^{-1}\right) \cdot H_{R_{0}}\left(z^{-1}\right),
\end{aligned}
$$

where $H_{S_{0}}\left(q^{-1}\right)$ and $H_{R_{0}}\left(q^{-1}\right)$ represent pre-specified parts of the controller (used for example to incorporate the internal model of a disturbance or to open the loop at certain frequencies) and $S_{0}^{\prime}\left(q^{-1}\right)$ and $R_{0}^{\prime}\left(q^{-1}\right)$ are computed.

\footnotetext{
${ }^{2}$ The complex variable $z^{-1}$ will be used to characterize the system's behaviour in the frequency domain and the delay operator $q^{-1}$ will be used for the time domain analysis.

${ }^{3}$ The disturbance passes through a so called primary path which is represented in this figure, and $p(t)$ is its output.

${ }^{4}$ The argument $\left(z^{-1}\right)$ will be omitted in some of the following equations to make them more compact.
} 
We define the output sensitivity function (the transfer function between the disturbance $p(t)$ and the output of the system $y(t))$ as

$$
S_{y p}\left(z^{-1}\right)=\frac{A\left(z^{-1}\right) S_{0}\left(z^{-1}\right)}{P_{0}\left(z^{-1}\right)}
$$

and the input sensitivity function (the transfer function between the disturbance $p(t)$ and the control input $u(t))$ as

$$
S_{u p}\left(z^{-1}\right)=-\frac{A\left(z^{-1}\right) R\left(z^{-1}\right)}{P_{0}\left(z^{-1}\right)},
$$

where

$$
P_{0}\left(z^{-1}\right)=A\left(z^{-1}\right) S_{0}\left(z^{-1}\right)+z^{-d} B\left(z^{-1}\right) R_{0}\left(z^{-1}\right),
$$

the characteristic polynomial, specifies the desired closed loop poles of the system ${ }^{5}$ (see also [23]). It is important to remark that one should only reject disturbances located in frequency regions where the plant model has enough gain. This can be seen by looking at eq. (9) and noticing that perfect rejection at a certain frequency, $\omega_{0}$, is obtained iff $S_{0}\left(e^{-j \omega_{0}}\right)=0$. On the other hand, from eq. (10) one can see that this has a bad effect on the control input if the gain of the secondary path is too small at $\omega_{0}$.

In this paper, the Youla-Kučera parametrization ([3], [27]) is used. Supposing a finite impulse response (FIR) representation of the adaptive $Q$ filter

$$
Q\left(z^{-1}\right)=q_{o}+q_{1} z^{-1}+\ldots+q_{n_{Q}} z^{-n_{Q}}
$$

the controller's polynomials are:

$$
\begin{aligned}
& R=R_{0}+A Q H_{S_{0}} H_{R_{0}}, \\
& S=S_{0}-z^{-d} B Q H_{S_{0}} H_{R_{0}} .
\end{aligned}
$$

where $R_{0}$ and $S_{0}$ define the central controller which verifies the desired specifications in the absence of the disturbance. The characteristic polynomial of the closed loop becomes

$$
P=A S_{0}+z^{-d} B R_{0} .
$$

\section{Direct Adaptive Regulation for Disturbance REJECTION}

This section presents the direct adaptive control algorithm ([22], [21]) that will be used for the benchmark problem. A key aspect of this methodology is the use of the IMP. It is supposed that $p(t)$ is a deterministic disturbance given by

$$
p(t)=\frac{N_{p}\left(q^{-1}\right)}{D_{p}\left(q^{-1}\right)} \cdot \delta(t),
$$

where $\delta(t)$ is a Dirac impulse and $N_{p}, D_{p}$ are coprime polynomials of degrees $n_{N_{p}}$ and $n_{D_{p}}$, respectively ${ }^{6}$. In the case of stationary narrow-band disturbances, the roots of $D_{p}\left(z^{-1}\right)$ are on the unit circle and the contribution of the terms of $N_{p}$ can be neglected.

\footnotetext{
${ }^{5}$ It is assumed that a reliable model identification is achieved and therefore the estimated model is assumed to be equal to the true model.

${ }^{6}$ Throughout the paper, $n_{X}$ denotes the degree of the polynomial $X$.
}

Internal Model Principle: The effect of the disturbance given in (16) upon the output

$$
y(t)=\frac{A\left(q^{-1}\right) S\left(q^{-1}\right)}{P\left(q^{-1}\right)} \cdot \frac{N_{p}\left(q^{-1}\right)}{D_{p}\left(q^{-1}\right)} \cdot \delta(t),
$$

where $D_{p}\left(z^{-1}\right)$ is a polynomial with roots on the unit circle and $P\left(z^{-1}\right)$ is an asymptotically stable polynomial, converges asymptotically towards zero iff the polynomial $S\left(z^{-1}\right)$ in the $R S$ controller has the form (based on eq. (7))

$$
S\left(z^{-1}\right)=D_{p}\left(z^{-1}\right) H_{S_{0}}\left(z^{-1}\right) S^{\prime}\left(z^{-1}\right) .
$$

Thus, the pre-specified part of $S\left(z^{-1}\right)$ should be chosen as $H_{S}\left(z^{-1}\right)=D_{p}\left(z^{-1}\right) H_{S_{0}}\left(z^{-1}\right)$ and the controller is computed solving

$$
P=A D_{p} H_{S_{0}} S^{\prime}+z^{-d} B H_{R_{0}} R^{\prime},
$$

where $P, D_{p}, A, B, H_{R_{0}}, H_{S_{0}}$ and $d$ are given ${ }^{7}$.

To compute $Q\left(z^{-1}\right)$ in order that the polynomial $S\left(z^{-1}\right)$ given by (14) incorporates the internal model of the disturbance (18), one has to solve the diophantine equation

$$
S^{\prime} D_{p}+z^{-d} B H_{R_{0}} Q=S_{0}^{\prime},
$$

where $D_{p}, d, B, S_{0}^{\prime}$, and $H_{R_{0}}$ are known and $S^{\prime}$ and $Q$ are unknown. Eq. (20) has a unique solution for $S^{\prime}$ and $Q$ with: $n_{S_{0}^{\prime}} \leq n_{D_{p}}+n_{B}+d+n_{H_{R_{0}}}-1, n_{S^{\prime}}=n_{B}+d+n_{H_{R_{0}}}-1$, $n_{Q}=n_{D_{p}}-1$. One sees that the order $n_{Q}$ of the polynomial $Q$ depends upon the structure of the disturbance model. The use of the Youla-Kučera parametrization, with $Q$ given in (12), is interesting because it allows to maintain the closed loop poles as given by the central controller but at the same time introduce the parameters of the internal model into the controller. The development of the parametric adaptation algorithm (PAA) requires first find an error equation (see also [27], [22], [21]). Using the $Q$-parametrization, the output of the system in the presence of a disturbance can be expressed as

$$
\begin{aligned}
y(t) & =\frac{A\left[S_{0}-q^{-d} B H_{S_{0}} H_{R_{0}} Q\right]}{P} \cdot \frac{N_{p}}{D_{p}} \cdot \delta(t) \\
& =\frac{S_{0}-q^{-d} B H_{S_{0}} H_{R_{0}} Q}{P} \cdot w(t),
\end{aligned}
$$

where $w(t)$ is given by (see also Fig. 3)

$$
w(t)=\frac{A N_{p}}{D_{p}} \cdot \delta(t)=A \cdot y(t)-q^{-d} \cdot B \cdot u(t) .
$$

Taking into consideration that the adaptation of $Q$ is done in order to obtain an output $y(t)$ which tends asymptotically to zero, one can define $\varepsilon^{0}(t+1)$ as the value of $y(t+1)$ obtained with $\hat{Q}\left(t, q^{-1}\right)$ (the estimate of $Q$ at time $t$, written also $\hat{Q}(t)$ )

$$
\varepsilon^{0}(t+1)=\frac{S_{0}}{P} \cdot w(t+1)-\hat{Q}(t) \frac{q^{-d} B^{*} H_{S_{0}} H_{R_{0}}}{P} \cdot w(t) .
$$

Similarly, the a posteriori error becomes (using $\hat{Q}(t+1)$ ) as

$$
\varepsilon(t+1)=\frac{S_{0}}{P} \cdot w(t+1)-\hat{Q}(t+1) \frac{q^{-d} B^{*} H_{S_{0}} H_{R_{0}}}{P} \cdot w(t) .
$$

${ }^{7}$ Of course, it is assumed that $D_{p}$ and $B$ do not have common factors. 
Replacing $S_{0}$ from the last equation by (20), one obtains

$$
\varepsilon(t+1)=[Q-\hat{Q}(t+1)] \cdot \frac{q^{-d} B^{*} H_{S_{0}} H_{R_{0}}}{P} \cdot w(t)+v(t+1),
$$

where

$$
v(t)=\frac{S^{\prime} D_{p} H_{S_{0}}}{P} \cdot w(t)=\frac{S^{\prime} H_{S_{0}} A N_{p}}{P} \cdot \delta(t)
$$

is a signal which tends asymptotically towards zero.

Define the estimated polynomial $\hat{Q}\left(t, q^{-1}\right)=\hat{q}_{0}(t)+$ $\hat{q}_{1}(t) q^{-1}+\ldots+\hat{q}_{n_{Q}}(t) q^{-n_{Q}}$ and the associated estimated parameter vector $\hat{\theta}(t)=\left[\begin{array}{llll}\hat{q}_{0}(t) & \hat{q}_{1}(t) & \ldots & \hat{q}_{n_{Q}}(t)\end{array}\right]^{T}$. Define the fixed parameter vector corresponding to the optimal value of the polynomial $Q$ as: $\theta=\left[\begin{array}{llll}q_{0} & q_{1} & \ldots & q_{n_{Q}}\end{array}\right]^{T}$.

Denote

$$
w_{2}(t)=\frac{q^{-d} B^{*} H_{S_{0}} H_{R_{0}}}{P} \cdot w(t)
$$

and define the following observation vector

$$
\phi^{T}(t)=\left[\begin{array}{llll}
w_{2}(t) & w_{2}(t-1) & \ldots & w_{2}\left(t-n_{Q}\right)
\end{array}\right] .
$$

Eq. (25) becomes

$$
\varepsilon(t+1)=\left[\theta^{T}-\hat{\theta}^{T}(t+1)\right] \cdot \phi(t)+v(t+1) .
$$

One can remark that $\varepsilon(t+1)$ corresponds to an adaptation error ([18]).

From eq. (23), one obtains the a priori adaptation error

$$
\varepsilon^{0}(t+1)=w_{1}(t+1)-\hat{\theta}^{T}(t) \phi(t)
$$

with

$$
\begin{aligned}
w_{1}(t+1) & =\frac{S_{0}\left(q^{-1}\right)}{P\left(q^{-1}\right)} \cdot w(t+1), \\
w(t+1) & =A\left(q^{-1}\right) \cdot y(t+1)-q^{-d} B^{*}\left(q^{-1}\right) \cdot u(t),
\end{aligned}
$$

where $B\left(q^{-1}\right) u(t+1)=B^{*}\left(q^{-1}\right) u(t)$.

The a posteriori adaptation error is obtained from (24)

$$
\varepsilon(t+1)=w_{1}(t+1)-\hat{\theta}^{T}(t+1) \phi(t) .
$$

For the estimation of the parameters of $\hat{Q}\left(t, q^{-1}\right)$ the following PAA is used ([18]):

$$
\begin{aligned}
\hat{\theta}(t+1) & =\hat{\theta}(t)+F(t) \phi(t) \varepsilon(t+1), \\
\varepsilon(t+1) & =\frac{\varepsilon^{0}(t+1)}{1+\phi^{T}(t) F(t) \phi(t)}, \\
\varepsilon^{0}(t+1) & =w_{1}(t+1)-\hat{\theta}^{T}(t) \phi(t), \\
F(t+1) & =\frac{1}{\lambda_{1}(t)}\left[F(t)-\frac{F(t) \phi(t) \phi^{T}(t) F(t)}{\frac{\lambda_{1}(t)}{\lambda_{2}(t)}+\phi^{T}(t) F(t) \phi(t)}\right], \\
1 & \geq \lambda_{1}(t)>0,0 \leq \lambda_{2}(t)<2,
\end{aligned}
$$

where $\lambda_{1}(t), \lambda_{2}(t)$ allow to obtain various profiles for the evolution of the adaptation gain $F(t)$ (for details see [18], [23]).

\section{Central Controller Design}

The central controller plays a relevant role in this approach, making of it a key element. Its role is to stabilize the system in the absence of disturbances and to allow to obtain a small amplification outside the attenuation frequencies, when the adaptive regulation algorithm is active. The central controller was presented in eqs. (7) and (8) and is indicated in Fig. 3.

Since the amplifications outside the attenuation frequencies are reflected in the output sensitivity function $\left(S_{y p}\left(z^{-1}\right)\right)$, the technique of pole placement with sensitivity function shaping is an option to address the problem (see details in [23]). The benchmark specifications propose a frequency region of interest from 50 to $95 \mathrm{~Hz}$. Considering this region as a band it is possible to shape the sensitivity functions through a bandpass filter approach, in order to minimize the effect of the IMP design. This is achieved by introducing fixed auxiliary low damped poles near to the frequency limits of the band of interest. The damping factor of these poles has to be chosen in a way that the effect of the IMP will not be eliminated, just attenuated. To preserve the robustness and dynamics, all the poles of the system are conserved.

From eqs. (8) and (7), the central controller can incorporate fixed parts for specific purposes. In [21] it is shown how to preserve the fixed parts of the central controller using a YK parametrization. Following this approach and considering the characteristics of BSFs (see details in [23] and [25]), a reduction in the modulus of $S_{u p}\left(z^{-1}\right)$ for higher frequencies can be imposed (for example, see Fig. 4) without introducing undesired effects on $S_{y p}\left(z^{-1}\right)$. This improves the robustness by reducing the effects of the IMP design outside the frequency band of interest.
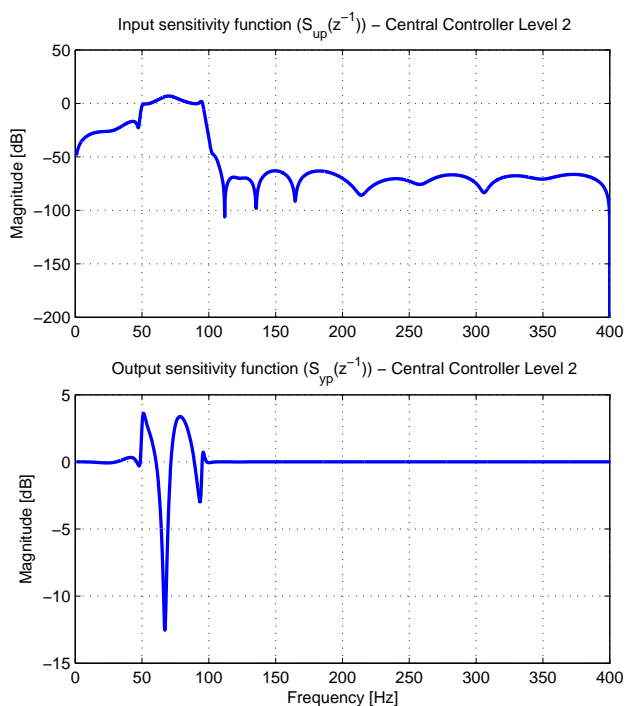

Fig. 4. Sensitivity functions for Level 2

To accomplish this, the BSFs' transfer function numerator $\left(n_{B S F}\left(z^{-1}\right)\right)$ is implemented on the fixed part of the controller's 
numerator polynomial ${ }^{8}$,

$$
H_{R_{0}}=H_{R_{0}}^{\prime} n_{B S F},
$$

while the BSF transfer function denominator $\left(d_{B S F}\left(z^{-1}\right)\right)$ will define additional closed loop poles. No fixed parts were considered for $S_{0}\left(z^{-1}\right)$.

\section{Vi. Simulation Results}

According to [20], [19], the benchmark's specifications consider three levels in terms of the number of narrow band disturbances to be rejected (attenuated). For each level, three types of tests were designed for which performance specifications have to be achieved.

The first series of tests, called Simple Step Test, deals with global attenuation ( $\mathrm{GA}$ in $\mathrm{dB}$ ), disturbance attenuation (DA in $\mathrm{dB}$ ), maximum amplification (MA in $\mathrm{dB}$ ) outside the attenuation frequencies (these quantities are evaluated once the adaptation has settled), transient duration (TD in sec), maximum value (MV in Volts) during transient, a measure of the integral of the square error during transient $\left(N^{2} T\right)$, and after settling of the adaptation $\left(N^{2} R\right)$. The second series of tests consider the evaluation of performances for step changes in frequencies and the third consider the evaluation of performances when the disturbances are chirp signals.

\section{A. Level 1 Results}

The Table I shows the results obtained in the presence of one sinusoidal disturbance with constant frequency (Simple Step Test). The benchmark specifications for global attenuation and disturbance attenuation ${ }^{9}$ are passed at all frequencies. The maximum amplifications obtained are slightly over the limit $(6 \mathrm{~dB})$, while the transient duration is lower than 2 seconds. The Table II resume the results obtained when the disturbance frequency changes (Step Changes Frequency Test) showing in general fast transients (lower than 2 seconds) without increasing the maximum values.

The third test consist in applying a chirp signal as disturbance. The results are in the Table III. The two periods of chirp are indicated as $\nearrow$ (for increasing frequency) and $\searrow$ (for decreasing frequency). The benchmark requirement is that the maximum value of the residual force (output of the system) is not greater than $0.1 \mathrm{~V}$. One can see that the benchmark specifications are satisfied.

\section{B. Level 2 Results}

The Level 2 increases the difficulty but the compromise achieved between attenuation and amplification is demonstrated in Table I, where the simulation results for simple step test are presented. Both specifications, global attenuation and disturbance attenuation, were satisfied. The maximum amplification is in some cases marginally over the limit $(7 \mathrm{~dB}$ for this level). For step changes frequency test, the increments in the transient time (see Table IV) do not pass the benchmark limit. The chirp requirement is also fulfilled for this level (Table V).

\footnotetext{
${ }^{8} H_{R_{0}}^{\prime}$ is used for opening the loop at $0 f_{s}$ and $0.5 f_{s}$

${ }^{9}$ At $95 \mathrm{~Hz}$ the disturbance attenuation is marginally below the benchmark specification for the three levels.
}

TABLE II

Simulation Results - LeVEl 1 - Step Changes FREQUENCY TEST

\begin{tabular}{|c|c|c|c|}
\hline \multicolumn{4}{|c|}{ SEQUENCE - 1} \\
\hline $\begin{array}{c}\text { Frequency } \\
(\mathbf{H z})\end{array}$ & $\begin{array}{c}\text { Norm }^{2} \text { Trans. } \\
\quad\left(\times 10^{-3}\right)\end{array}$ & $\begin{array}{c}\text { Max. Val. } \\
\left(\times 10^{-3}\right)\end{array}$ & $\begin{array}{c}\text { Transient } \\
\text { (msec) }\end{array}$ \\
\hline $60 \rightarrow 70$ & 17.127 & 22.155 & 110.00 \\
\hline $70 \rightarrow 60$ & 16.948 & 16.101 & 106.25 \\
\hline $60 \rightarrow 50$ & 46.205 & 18.719 & 143.75 \\
\hline $50 \rightarrow 60$ & 41.759 & 30.724 & 143.75 \\
\hline \multicolumn{4}{|c|}{ SEQUENCE - 2} \\
\hline $\begin{array}{c}\text { Frequency } \\
\text { (Hz) }\end{array}$ & $\begin{array}{l}\text { Norm }^{2} \text { Trans. } \\
\quad\left(\times 10^{-3}\right)\end{array}$ & $\begin{array}{c}\text { Max. Val. } \\
\left(\times 10^{-3}\right)\end{array}$ & $\begin{array}{c}\text { Transient } \\
\text { (msec) }\end{array}$ \\
\hline $75 \rightarrow 85$ & 16.738 & 15.657 & 132.50 \\
\hline $85 \rightarrow 75$ & 15.422 & 18.571 & 126.25 \\
\hline $75 \rightarrow 65$ & 14.178 & 15.091 & 121.25 \\
\hline $65 \rightarrow 75$ & 14.246 & 17.137 & 103.75 \\
\hline \multicolumn{4}{|c|}{ SEQUENCE - 3} \\
\hline $\begin{array}{c}\text { Frequency } \\
(\mathrm{Hz})\end{array}$ & $\begin{array}{c}\text { Norm }^{2} \text { Trans. } \\
\left(\times 10^{-3}\right)\end{array}$ & $\begin{array}{c}\text { Max. Val. } \\
\left(\times 10^{-3}\right)\end{array}$ & $\begin{array}{c}\text { Transient } \\
\text { (msec) }\end{array}$ \\
\hline $85 \rightarrow 95$ & 39.322 & 23.835 & 30.00 \\
\hline $95 \rightarrow 85$ & 32.884 & 28.047 & 98.75 \\
\hline $85 \rightarrow 75$ & 15.447 & 21.127 & 93.75 \\
\hline $75 \rightarrow 85$ & 16.307 & 15.769 & 126.25 \\
\hline
\end{tabular}

TABLE III

Simulation Results - LEVEl 1 - ChIRP TEST

\begin{tabular}{|c|c|c|}
\hline & Error-Mean Square Value & Error-Maximum Value \\
\hline$\nearrow$ & $14.499 \times 10^{-6}$ & $13.963 \times 10^{-3}$ \\
\hline$\searrow$ & $14.0 \times 10^{-6}$ & $14.860 \times 10^{-3}$ \\
\hline
\end{tabular}

TABLE IV

Simulation Results - LEVEL 2 - Step Changes FREQUENCY TEST

\begin{tabular}{|c|c|c|c|}
\hline \multicolumn{5}{|c|}{ SEQUENCE - 1 } \\
\hline $\begin{array}{c}\text { Frequency } \\
(\mathbf{H z})\end{array}$ & $\begin{array}{c}\text { Norm }^{2} \text { Trans. } \\
\left(\times 10^{-3}\right)\end{array}$ & $\begin{array}{c}\text { Max. Val. } \\
\left(\times 10^{-3}\right)\end{array}$ & $\begin{array}{c}\text { Transient } \\
(\mathbf{m s e c})\end{array}$ \\
\hline$[55,75] \rightarrow[60,80]$ & 38.334 & 34.663 & 208.75 \\
\hline$[60,80] \rightarrow[55,75]$ & 36.202 & 30.359 & 206.25 \\
\hline$[55,75] \rightarrow[50,70]$ & 78.016 & 35.463 & 263.75 \\
\hline$[50,70] \rightarrow[55,75]$ & 70.110 & 39.072 & 165.00 \\
\hline \multicolumn{4}{|c|}{ SEQUENCE - 2 } \\
\hline $\begin{array}{c}\text { Frequency } \\
(\mathbf{H z})\end{array}$ & $\begin{array}{c}\text { Norm }^{2} \text { Trans. } \\
\left(\times 10^{-3}\right)\end{array}$ & $\begin{array}{c}\text { Max. Val. } \\
\left(\times 10^{-3}\right)\end{array}$ & $\begin{array}{c}\text { Transient } \\
(\text { msec })\end{array}$ \\
\hline$[70,90] \rightarrow[75,95]$ & 60.982 & 30.850 & 262.50 \\
\hline$[75,95] \rightarrow[70,90]$ & 66.667 & 40.396 & 193.75 \\
\hline$[70,90] \rightarrow[65,85]$ & 39.498 & 34.570 & 198.75 \\
\hline$[65,85] \rightarrow[70,90]$ & 39.364 & 29.374 & 210.00 \\
\hline
\end{tabular}

TABLE V

Simulation Results - LEVEL 2 - ChiRP TEST

\begin{tabular}{|c|c|c|}
\hline & Error-Mean Square Value & Error-Maximum Value \\
\hline$\nearrow$ & $42.465 \times 10^{-6}$ & $19.443 \times 10^{-3}$ \\
\hline$\searrow$ & $42.104 \times 10^{-6}$ & $19.860 \times 10^{-3}$ \\
\hline
\end{tabular}

\section{Level 3 Results}

The third level considers three narrow band disturbances and is on this level where the advantages of the approach used for the central controller design are shown. Generally speaking, all the benchmark specifications were satisfied at this level, as can bee seen from the Tables I, VI and VII.

\section{EXPERIMENTAL RESULTS}

In this section the real-time results are presented. The same central controllers and adaptation gains used in simulation 
TABLE I

Simulation Results - Simple Step Test

\begin{tabular}{|c|c|c|c|c|c|c|c|}
\hline \multicolumn{8}{|c|}{ LEVEL 1} \\
\hline $\begin{array}{c}\text { Frequency } \\
(\mathbf{H z})\end{array}$ & $\begin{array}{c}\text { Global } \\
\text { (dB) }\end{array}$ & $\begin{array}{l}\text { Dist. Atte. } \\
\text { (dB) }\end{array}$ & $\begin{array}{c}\text { Max. Amp. } \\
(\text { dB@Hz) }\end{array}$ & $\begin{array}{c}\text { Norm }^{2} \text { Trans. } \\
\left(\times 10^{-3}\right)\end{array}$ & $\begin{array}{c}\text { Norm }^{2} \text { Res. } \\
\left(\times 10^{-3}\right)\end{array}$ & $\begin{array}{l}\text { Max. Val. } \\
\left(\times 10^{-3}\right)\end{array}$ & $\begin{array}{l}\text { Trans. } \\
\text { (msec) }\end{array}$ \\
\hline 50 & 34.17 & 44.43 & $7.21 @ 67.18$ & 14.478 & 3.751 & 17.675 & 248.750 \\
\hline 55 & 32.78 & 46.84 & 6.66@78.12 & 10.146 & 4.432 & 19.895 & 88.750 \\
\hline 60 & 32.30 & 46.94 & $6.76 @ 82.81$ & 10.226 & 4.685 & 20.136 & 73.750 \\
\hline 65 & 32.77 & 48.38 & $6.95 @ 50.00$ & 9.296 & 4.512 & 19.905 & 52.500 \\
\hline 70 & 33.29 & 50.04 & 7.84@53.13 & 8.314 & 4.300 & 19.939 & 41.250 \\
\hline 75 & 34.01 & 51.90 & $7.31 @ 53.13$ & 7.923 & 4.048 & 19.817 & 45.000 \\
\hline 80 & 34.57 & 51.56 & $7.65 @ 93.75$ & 8.161 & 3.750 & 21.749 & 43.750 \\
\hline 85 & 34.39 & 52.29 & 6.70@64.06 & 9.753 & 3.697 & 23.902 & 75.000 \\
\hline 90 & 31.94 & 44.98 & 7.46@68.75 & 13.335 & 4.037 & 26.842 & 121.250 \\
\hline 95 & 23.87 & 35.70 & $6.17 @ 87.50$ & 20.764 & 4.550 & 29.124 & 305.00 \\
\hline \multicolumn{8}{|c|}{ LEVEL 2} \\
\hline $\begin{array}{c}\text { Frequency } \\
(\mathbf{H z})\end{array}$ & $\begin{array}{l}\text { Global } \\
\text { (dB) }\end{array}$ & $\begin{array}{l}\text { Dist. Atte. } \\
\text { (dB)-(dB) }\end{array}$ & $\begin{array}{c}\text { Max. Amp. } \\
(\text { dB @Hz) }\end{array}$ & $\begin{array}{c}\text { Norm }^{2} \text { Trans. } \\
\quad\left(\times 10^{-3}\right)\end{array}$ & $\begin{array}{c}\text { Norm }{ }^{2} \text { Res. } \\
\left(\times 10^{-3}\right)\end{array}$ & $\begin{array}{l}\text { Max. Val. } \\
\left(\times 10^{-3}\right)\end{array}$ & $\begin{array}{l}\text { Trans. } \\
\text { (msec) }\end{array}$ \\
\hline $50-70$ & 39.16 & $41.81-47.49$ & $6.11 @ 79.69$ & 25.035 & 4.258 & 29.441 & 171.25 \\
\hline $55-75$ & 38.35 & $48.33-47.66$ & 7.74@87.50 & 23.392 & 4.747 & 34.729 & 136.25 \\
\hline $60-80$ & 39.42 & $50.14-49.26$ & $7.87 @ 50.00$ & 19.405 & 4.170 & 34.186 & 90.00 \\
\hline 65-85 & 39.83 & $49.13-51.04$ & 7.24@53.13 & 18.266 & 3.941 & 36.547 & 97.50 \\
\hline $70-90$ & 38.45 & $51.49-42.59$ & $7.61 @ 59.37$ & 27.326 & 4.238 & 40.645 & 198.750 \\
\hline $75-95$ & 36.47 & $54.02-37.28$ & $6.06 @ 87.50$ & 35.621 & 4.061 & 44.513 & 197.50 \\
\hline \multicolumn{8}{|c|}{ LEVEL 3} \\
\hline $\begin{array}{c}\text { Frequency } \\
(\mathbf{H z})\end{array}$ & $\begin{array}{c}\text { Global } \\
\text { (dB) }\end{array}$ & $\begin{array}{c}\text { Dist. Atte. } \\
\text { (dB)-(dB)-(dB) }\end{array}$ & $\begin{array}{l}\text { Max. Amp. } \\
(\text { dB@Hz) }\end{array}$ & $\begin{array}{l}\text { Norm }^{2} \text { Trans. } \\
\quad\left(\times 10^{-3}\right)\end{array}$ & $\begin{array}{c}\text { Norm }{ }^{2} \text { Res. } \\
\left(\times 10^{-3}\right)\end{array}$ & $\begin{array}{l}\text { Max. Val. } \\
\left(\times 10^{-3}\right)\end{array}$ & $\begin{array}{l}\text { Trans. } \\
\text { (msec) }\end{array}$ \\
\hline $50-65-80$ & 42.72 & $40.29-41.46-40.79$ & $7.63 @ 87.50$ & 117.834 & 4.251 & 66.905 & 566.250 \\
\hline $55-70-85$ & 42.98 & $47.36-47.86-46.42$ & $7.56 @ 76.56$ & 262.424 & 4.104 & 112.903 & 518.750 \\
\hline 60-75-90 & 41.96 & $46.33-48.62-39.75$ & 8.43@51.56 & 359.209 & 4.375 & 158.195 & 585.000 \\
\hline $65-80-95$ & 40.93 & $44.40-42.29-35.13$ & 7.88@73.43 & 753.370 & 4.141 & 235.072 & 657.500 \\
\hline
\end{tabular}

TABLE VI

Simulation Results - LeVel 3 - Step Changes FREQUENCY TEST

\begin{tabular}{|c|c|c|c|}
\hline \multicolumn{4}{|c|}{ SEQUENCE - 1 } \\
\hline $\begin{array}{c}\text { Frequency } \\
(\mathbf{H z})\end{array}$ & $\begin{array}{c}\text { Norm }^{2} \text { Trans. } \\
\left(\times 10^{-3}\right)\end{array}$ & $\begin{array}{c}\text { Max. Val. } \\
\left(\times 10^{-3}\right)\end{array}$ & $\begin{array}{c}\text { Transient } \\
(\mathbf{m s e c})\end{array}$ \\
\hline$[55,70,85] \rightarrow[60,75,90]$ & 221.36 & 52.324 & 410.00 \\
\hline$[60,75,90] \rightarrow[55,70,85]$ & 170.29 & 55.00 & 398.75 \\
\hline$[55,70,85] \rightarrow[50,65,80]$ & 270.26 & 61.669 & 482.50 \\
\hline$[50,65,80] \rightarrow[55,70,85]$ & 195.22 & 63.247 & 338.75 \\
\hline \multicolumn{4}{|c|}{ SEQUENCE - 2 } \\
\hline$[60,75,90] \rightarrow[65,80,95]$ & 241.53 & 51.326 & 341.25 \\
\hline$[65,80,95] \rightarrow[60,75,90]$ & 187.52 & 67.680 & 338.75 \\
\hline$[60,75,90] \rightarrow[55,70,85]$ & 181.05 & 55.209 & 470.00 \\
\hline$[55,70,85] \rightarrow[60,75,90]$ & 198.20 & 51.033 & 343.75 \\
\hline
\end{tabular}

TABLE VII

Simulation Results - LeVEl 3 - ChiRP TEST

\begin{tabular}{|c|c|c|}
\hline & Error-Mean Square Value & Error-Maximum Value \\
\hline$\nearrow$ & $131.54 \times 10^{-6}$ & $44.252 \times 10^{-3}$ \\
\hline$\searrow$ & $118.3 \times 10^{-6}$ & $40.351 \times 10^{-3}$ \\
\hline
\end{tabular}

have been considered in this section.

\section{A. Level 1 Results}

Table VIII presents the simple step test results. The proximity between the simulation and real-time results is remarkable. The main differences are in the maximum amplification and transient duration. For the step changes frequency test (Table IX) the results are quite similar and significant differences weren't found. In the chirp case, the results are also close to the simulation ones (Table $\mathrm{X}$ ).
TABLE IX

EXPERIMENTAL RESUltS - LEVEL 1 - Step ChANGES FREQUENCY TEST

\begin{tabular}{|c|c|c|c|}
\hline \multicolumn{4}{|c|}{ SEQUENCE - 1} \\
\hline $\begin{array}{c}\text { Frequency } \\
(\mathbf{H z})\end{array}$ & $\begin{array}{c}\text { Norm }^{2} \text { Trans. } \\
\left(\times 10^{-3}\right)\end{array}$ & $\begin{array}{c}\text { Max. Val. } \\
\left(\times 10^{-3}\right)\end{array}$ & $\begin{array}{c}\text { Transient } \\
\text { (msec) }\end{array}$ \\
\hline $60 \rightarrow 70$ & 16.785 & 21.183 & 138.75 \\
\hline $70 \rightarrow 60$ & 16.803 & 19.259 & 122.5 \\
\hline $60 \rightarrow 50$ & 69.216 & 20.084 & 255 \\
\hline $50 \rightarrow 60$ & 46.052 & 33.437 & 170 \\
\hline \multicolumn{4}{|c|}{ SEQUENCE - 2} \\
\hline $\begin{array}{c}\text { Frequency } \\
(\mathbf{H z})\end{array}$ & $\begin{array}{c}\text { Norm }^{2} \text { Trans. } \\
\quad\left(\times 10^{-3}\right)\end{array}$ & $\begin{array}{c}\text { Max. Val. } \\
\left(\times 10^{-3}\right)\end{array}$ & $\begin{array}{c}\text { Transient } \\
\text { (msec) }\end{array}$ \\
\hline $75 \rightarrow 85$ & 15.955 & 15.056 & 143.75 \\
\hline $85 \rightarrow 75$ & 15.528 & 18.733 & 152.5 \\
\hline $75 \rightarrow 65$ & 14.55 & 18.032 & 98.75 \\
\hline $65 \rightarrow 75$ & 14.223 & 18.733 & 130 \\
\hline \multicolumn{4}{|c|}{ SEQUENCE - 3} \\
\hline $\begin{array}{c}\text { Frequency } \\
\text { (Hz) }\end{array}$ & $\begin{array}{c}\text { Norm }^{2} \text { Trans. } \\
\left(\times 10^{-3}\right)\end{array}$ & $\begin{array}{c}\text { Max. Val. } \\
\left(\times 10^{-3}\right)\end{array}$ & $\begin{array}{c}\text { Transient } \\
\text { (msec) }\end{array}$ \\
\hline $85 \rightarrow 95$ & 40.822 & 16.794 & 2.5 \\
\hline $95 \rightarrow 85$ & 30.727 & 23.647 & 168.75 \\
\hline $85 \rightarrow 75$ & 15.227 & 19.971 & 126.25 \\
\hline $75 \rightarrow 85$ & 16.044 & 14.343 & 150 \\
\hline
\end{tabular}

TABLE $X$

EXPERIMENTAL RESUltS - LEVEL 1 - CHIRP TEST

\begin{tabular}{|c|c|c|}
\hline & Error-Mean Square Value & Error-Maximum Value \\
\hline$\nearrow$ & $13.742 \times 10^{-6}$ & $15.015 \times 10^{-3}$ \\
\hline$\searrow$ & $13.943 \times 10^{-6}$ & $15.015 \times 10^{-3}$ \\
\hline
\end{tabular}

\section{B. Level 2 Results}

The similar behaviour is reflected in the Tables VIII, XI and XII, where the results are still close to the previous ones obtained in simulation. 
TABLE VIII

EXPERIMENTAL RESUltS - Simple Step TEST

\begin{tabular}{|c|c|c|c|c|c|c|c|}
\hline \multicolumn{8}{|c|}{ LEVEL 1} \\
\hline $\begin{array}{c}\text { Frequency } \\
(\mathbf{H z})\end{array}$ & $\begin{array}{c}\text { Global } \\
\text { (dB) }\end{array}$ & $\begin{array}{l}\text { Dist. Atte. } \\
\text { (dB) }\end{array}$ & $\begin{array}{c}\text { Max. Amp. } \\
(\text { dB@Hz) }\end{array}$ & $\begin{array}{c}\text { Norm }^{2} \text { Trans. } \\
\left(\times 10^{-3}\right)\end{array}$ & $\begin{array}{c}\text { Norm }^{2} \text { Res. } \\
\left(\times 10^{-3}\right)\end{array}$ & $\begin{array}{c}\text { Max. Val. } \\
\left(\times 10^{-3}\right)\end{array}$ & $\begin{array}{l}\text { Trans. } \\
\text { (msec) }\end{array}$ \\
\hline 50 & 34.60 & 38.49 & $9.83 @ 65.63$ & 14.478 & 4.88 & 13.86 & 392.50 \\
\hline 55 & 34.54 & 50.45 & 9.48@118.75 & 13.32 & 4.94 & 19.97 & 103.75 \\
\hline 60 & 33.34 & 49.49 & $8.23 @ 79.69$ & 14.72 & 5.16 & 21.19 & 81.25 \\
\hline 65 & 32.78 & 50.04 & $9.65 @ 90.63$ & 14.17 & 4.53 & 20.50 & 120.00 \\
\hline 70 & 30.54 & 47.90 & $9.01 @ 89.06$ & 14.73 & 4.87 & 22.96 & 113.75 \\
\hline 75 & 29.53 & 45.54 & $8.90 @ 50.00$ & 11.20 & 4.86 & 19.28 & 57.50 \\
\hline 80 & 30.28 & 48.72 & 8.49@95.31 & 8.14 & 4.17 & 21.14 & 43.750 \\
\hline 85 & 28.47 & 45.94 & 10.66@57.81 & 10.05 & 6.90 & 25.14 & 22.50 \\
\hline 90 & 28.02 & 42.65 & 8.24@73.44 & 17.08 & 6.94 & 25.11 & 110.00 \\
\hline 95 & 24.63 & 34.55 & $9.06 @ 82.81$ & 50.09 & 8.33 & 32.44 & 616.25 \\
\hline \multicolumn{8}{|c|}{ LEVEL 2} \\
\hline $\begin{array}{c}\text { Frequency } \\
(\mathbf{H z})\end{array}$ & $\begin{array}{c}\text { Global } \\
\text { (dB) }\end{array}$ & $\begin{array}{l}\text { Dist. Atte. } \\
\text { (dB)-(dB) }\end{array}$ & $\begin{array}{c}\text { Max. Amp. } \\
\text { (dB@Hz) }\end{array}$ & $\begin{array}{c}\text { Norm }^{2} \text { Trans. } \\
\left(\times 10^{-3}\right)\end{array}$ & $\begin{array}{c}\text { Norm }^{2} \text { Res. } \\
\left(\times 10^{-3}\right)\end{array}$ & $\begin{array}{c}\text { Max. Val. } \\
\left(\times 10^{-3}\right)\end{array}$ & $\begin{array}{l}\text { Trans. } \\
\text { (msec) }\end{array}$ \\
\hline $50-70$ & 34.42 & $33.58-42.90$ & 8.32@59.38 & 32.10 & 9.35 & 29.02 & 393.75 \\
\hline $55-75$ & 33.27 & $44.90-44.18$ & 11.85@115.63 & 32.49 & 8.04 & 30.23 & 212.50 \\
\hline $60-80$ & 33.42 & $45.59-41.70$ & 7.78@118.75 & 31.35 & 7.08 & 28.99 & 230 \\
\hline 65-85 & 31.72 & $40.01-43.66$ & $8.02 @ 106.25$ & 22.75 & 7.62 & 31.44 & 112.50 \\
\hline $70-90$ & 32.91 & $41.43-38.63$ & 7.52@59.38 & 21.38 & 6.05 & 33.90 & 192.50 \\
\hline $75-95$ & 31.04 & $48.89-34.66$ & $7.09 @ 87.50$ & 28.33 & 6.65 & 38.40 & 222.50 \\
\hline \multicolumn{8}{|c|}{ LEVEL 3} \\
\hline $\begin{array}{c}\text { Frequency } \\
(\mathbf{H z})\end{array}$ & $\begin{array}{c}\text { Global } \\
\text { (dB) }\end{array}$ & $\begin{array}{c}\text { Dist. Atte. } \\
\text { (dB)-(dB)-(dB) }\end{array}$ & $\begin{array}{l}\text { Max. Amp. } \\
(\mathbf{d B} @ \mathbf{H z})\end{array}$ & $\begin{array}{l}\text { Norm }^{2} \text { Trans. } \\
\quad\left(\times 10^{-3}\right)\end{array}$ & $\begin{array}{c}\text { Norm }^{2} \text { Res. } \\
\left(\times 10^{-3}\right)\end{array}$ & $\begin{array}{c}\text { Max. Val. } \\
\left(\times 10^{-3}\right)\end{array}$ & $\begin{array}{l}\text { Trans. } \\
\text { (msec) }\end{array}$ \\
\hline $50-65-80$ & 42.73 & $37.69-44.32-41.98$ & 9.10@71.88 & 536.57 & 7.06 & 129.54 & 786.25 \\
\hline $55-70-85$ & 42.68 & $42.29-45.51-46.14$ & $9.27 @ 93.75$ & $1,260.60$ & 5.86 & 225.17 & 1,375 \\
\hline 60-75-90 & 40.94 & $44.49-41.76-44.35$ & 11.30@68.75 & 310.35 & 6.44 & 87.36 & 820 \\
\hline $65-80-95$ & 35.99 & $44.27-42.29-31.50$ & $10.67 @ 87.50$ & $1,148.10$ & 7.25 & 143.77 & $1,433.80$ \\
\hline
\end{tabular}

TABLE XI

EXPERIMENTAL RESUlTS - LEVEL 2 - SteP ChANGES FREQUENCY TEST

\begin{tabular}{|c|c|c|c|}
\hline \multicolumn{5}{|c|}{ SEQUENCE - 1 } \\
\hline $\begin{array}{c}\text { Frequency } \\
(\mathbf{H z})\end{array}$ & $\begin{array}{c}\text { Norm }^{2} \text { Trans. } \\
\left(\times 10^{-3}\right)\end{array}$ & $\begin{array}{c}\text { Max. Val. } \\
\left(\times 10^{-3}\right)\end{array}$ & $\begin{array}{c}\text { Transient } \\
(\mathbf{m s e c})\end{array}$ \\
\hline$[55,75] \rightarrow[60,80]$ & 38.575 & 35.17 & 210 \\
\hline$[60,80] \rightarrow[55,75]$ & 38.506 & 31.007 & 160 \\
\hline$[55,75] \rightarrow[50,70]$ & 117.28 & 40.072 & 315 \\
\hline$[50,70] \rightarrow[55,75]$ & 69.186 & 43.262 & 157.5 \\
\hline \multicolumn{4}{|c|}{ SEQUENCE $-2^{-2}$} \\
\hline $\begin{array}{c}\text { Frequency } \\
(\text { Hz })\end{array}$ & $\begin{array}{c}\text { Norm } \\
\left(\times 10^{-3}\right)\end{array}$ & $\begin{array}{c}\text { Max. Val. } \\
\left(\times 10^{-3}\right)\end{array}$ & $\begin{array}{c}\text { Transient } \\
(\mathbf{m s e c})\end{array}$ \\
\hline$[70,90] \rightarrow[75,95]$ & 66.517 & 32.699 & 215 \\
\hline$[75,95] \rightarrow[70,90]$ & 60.013 & 33.827 & 205 \\
\hline$[70,90] \rightarrow[65,85]$ & 42.56 & 35.15 & 166.25 \\
\hline$[65,85] \rightarrow[70,90]$ & 42.946 & 28.575 & 216.25 \\
\hline
\end{tabular}

TABLE XII

EXPERIMENTAL RESUlTS - LEVEL 2 - CHIRP TEST

\begin{tabular}{|c|c|c|}
\hline & Error-Mean Square Value & Error-Maximum Value \\
\hline$\nearrow$ & $41.277 \times 10^{-6}$ & $21.624 \times 10^{-3}$ \\
\hline$\searrow$ & $42.379 \times 10^{-6}$ & $21.228 \times 10^{-3}$ \\
\hline
\end{tabular}

\section{Level 3 Results}

Finally, the most difficult level shows that the direct adaptive algorithm along with a central controller tuned with BSFs, presents a good performance regarding the benchmark specifications. This is confirmed in Tables VIII, XIII and XIV. From the simulation and real-time results, we can conclude that the frequency limits $(50$ and $95 \mathrm{~Hz})$ are quite challenging due to the proximity of low damped complex zeros.
TABLE XIII

EXPERIMENTAL RESUltS - LEVEL 3 - Step Changes FREQUENCY TEST

\begin{tabular}{|c|c|c|c|}
\hline \multicolumn{4}{|c|}{ SEQUENCE - 1 } \\
\hline $\begin{array}{c}\text { Frequency } \\
(\mathbf{H z})\end{array}$ & $\begin{array}{c}\text { Norm }^{2} \text { Trans. } \\
\left(\times 10^{-3}\right)\end{array}$ & $\begin{array}{c}\text { Max. Val. } \\
\left(\times 10^{-3}\right)\end{array}$ & $\begin{array}{c}\text { Transient } \\
(\mathbf{m s e c})\end{array}$ \\
\hline$[55,70,85] \rightarrow[60,75,90]$ & 235.74 & 62.066 & 343.75 \\
\hline$[60,75,90] \rightarrow[55,70,85]$ & 208.75 & 55.581 & 278.75 \\
\hline$[55,70,85] \rightarrow[50,65,80]$ & 242.6 & 59.615 & 345 \\
\hline$[50,65,80] \rightarrow[55,70,85]$ & 235.63 & 76.772 & 282.5 \\
\hline \multicolumn{4}{|c|}{ SEQUENCE - 2 } \\
\hline$[60,75,90] \rightarrow[65,80,95]$ & 275.33 & 64.494 & 411.25 \\
\hline$[65,80,95] \rightarrow[60,75,90]$ & 225.24 & 56.829 & 400 \\
\hline$[60,75,90] \rightarrow[55,70,85]$ & 196.53 & 51.927 & 277.5 \\
\hline$[55,70,85] \rightarrow[60,75,90]$ & 183.17 & 54.69 & 350 \\
\hline
\end{tabular}

TABLE XIV

EXPERIMENTAL RESUlTS - LEVEL 3 - CHIRP TEST

\begin{tabular}{|c|c|c|}
\hline & Error-Mean Square Value & Error-Maximum Value \\
\hline$\nearrow$ & $158.15 \times 10^{-6}$ & $42.399 \times 10^{-3}$ \\
\hline$\searrow$ & $133.47 \times 10^{-6}$ & $52.203 \times 10^{-3}$ \\
\hline
\end{tabular}

\section{CONCLUDING REMARKS}

Good coherence has been found between the simulation and real-time results, since the same controllers and adaptation gains were used on both situations. This shows the robustness of the scheme and the reliability of the model identified for the plant. The initial statements were confirmed since the proposed scheme shows fast transient durations, simpleness (the polynomial $\hat{Q}\left(q^{-1}\right)$ is the only part estimated) and stability in closed loop. The computational complexity of the proposed algorithm is not very demanding. 


\section{REFERENCES}

[1] F. Ben Amara, P.T. Kabamba, and A.G. Ulsoy. Adaptive sinusoidal disturbance rejection in linear discrete-time systems - Part I: Theory. Journal of Dynamic Systems Measurement and Control, 121:648-654, 1999.

[2] F. Ben Amara, P.T. Kabamba, and A.G. Ulsoy. Adaptive sinusoidal disturbance rejection in linear discrete-time systems - Part II: Experiments. Journal of Dynamic Systems Measurement and Control, 121:655-659, 1999.

[3] B.D.O. Anderson. From Youla-Kucera to identification, adaptive and nonlinear control. Automatica, 34:1485-1506, 1998.

[4] G. Bengtsson. Output regulation and internal models - a frequency domain approach. Automatica, 13(4):333 - 345, 1977.

[5] L.L. Beranek and I.L. Ver. Noise and Vibration Control Engineering: Principles and Applications. Wiley, New York, 1992.

[6] M. Bodson. Rejection of periodic distrubances of unknown and timevarying frequency. Int. J. of Adapt. Contr. and Sign. Proc., 19:67-88, 2005.

[7] M. Bodson and S.C. Douglas. Adaptive algorithms for the rejection of sinusosidal disturbances with unknown frequency. Automatica, 33:22132221, 1997.

[8] $\mathrm{Xu}$ Chen and M. Tomizuka. A minimum parameter adaptive approach for rejecting multiple narrow-band disturbances with application to hard disk drives. Control Systems Technology, IEEE Transactions on, 20(2):408 -415, march 2012.

[9] Z. Ding. Global stabilization and disturbance suppression of a class of nonlinear systems with uncertain internal model. Automatica, 39(3):471 $-479,2003$.

[10] S.J. Elliott and P.A. Nelson. Active noise control. Noise / News International, pages 75-98, June 1994.

[11] S.J. Elliott and T.J. Sutton. Performance of feedforward and feedback systems for active control. Speech and Audio Processing, IEEE Transactions on, 4(3):214 -223, may 1996.

[12] G. Feng and M. Palaniswami. A stable adaptive implementation of the internal model principle. IEEE Trans. on Automatic Control, 37:12201225, 1992.

[13] B.A. Francis and W.M. Wonham. The internal model principle of control theory. Automatica, 12(5):457 - 465, 1976.

[14] C.R. Fuller and A.H. von Flotow. Active control of sound and vibration. Control Systems, IEEE, 15(6):9-19, dec 1995.

[15] T. Gouraud, M. Gugliemi, and F. Auger. Design of robust and frequency adaptive controllers for harmonic disturbance rejection in a single-phase power network. Proceedings of the European Control Conference, Bruxelles, 1997.

[16] G. Hillerstrom and J. Sternby. Rejection of periodic disturbances with unknown period - a frequency domain approach. Proceedings of American Control Conference, Baltimore, pages 1626-1631, 1994.

[17] C.D. Johnson. Theory of disturbance-accomodating controllers. In Control and Dynamical Systems (C. T. Leondes, Ed.), 1976. Vol. 12, pp. 387-489.

[18] I. D. Landau, R. Lozano, M. M'Saad, and A. Karimi. Adaptive control. Springer, London, 2nd edition, 2011

[19] I.D. Landau, T.B. Airimiţoaie, A. Castellanos Silva, and G. Buche. Benchmark on adaptive regulation. http://www.gipsa-lab.grenoble-inp. $\mathrm{fr} /$ ioandore.landau/benchmark_adaptive_regulation/.

[20] I.D. Landau, T.B. Airimiţoaie, A. Castellanos Silva, and G. Buche. Benchmark on adaptive regulation: Rejection of unknown/time-varying multiple narrow band disturbances. In Proceedings of the 12th biannual European Control Conference, Zürich, Suisse, 2013.

[21] I.D. Landau, M. Alma, J.J. Martinez, and G. Buche. Adaptive suppression of multiple time-varying unknown vibrations using an inertial actuator. Control Systems Technology, IEEE Transactions on, 19(6):1327 -1338 , nov. 2011.

[22] I.D. Landau, A. Constantinescu, and D. Rey. Adaptive narrow band disturbance rejection applied to an active suspension - an internal model principle approach. Automatica, 41(4):563-574, 2005.

[23] I.D. Landau and G. Zito. Digital Control Systems - Design, Identification and Implementation. Springer, London, 2005.

[24] R. Marino, G.L. Santosuosso, and P. Tomei. Robust adaptive compensation of biased sinusoidal disturbances with unknown frequency. Automatica, 39:1755-1761, 2003.

[25] Hynek Prochzka and Ioan Doré Landau. Pole placement with sensitivity function shaping using 2 nd order digital notch filters. Automatica, 39(6): 1103 - 1107, 2003.
[26] Z. Sun and T.C. Tsao. Adaptive control with asymptotic tracking performance and its application to an electro-hydraulic servo system. Journal of Dynamic Systems Measurement and Control, 122:188-195, 2000.

[27] Y.Z. Tsypkin. Stochastic discrete systems with internal models. Journal of Automation and Information Sciences, 29(4\&5):156-161, 1997.

[28] S. Valentinotti. Adaptive Rejection of Unstable Disturbances: Application to a Fed-Batch Fermentation. Thèse de doctorat, École Polytechnique Fédérale de Lausanne, April 2001.

[29] B. Widrow and S.D. Stearns. Adaptive Signal Processing. Prentice-Hall, Englewood Cliffs, New Jersey, 1985.

[30] Y. Zhang, P.G. Mehta, R. Bitmead, and C.R. Johnson. Direct adaptive control for tonal disturbance rejection. Proceedings of the American Control Conference, Philadelphia, pages 1480-1482, 1998. 